\title{
Kulturmöten mellan döva och hörande på arbetslivets arena
}

\author{
GUNNEL BACKENROTH-OHSAKO
}

\author{
Många kulturmöten äger rum i arbetslivet. Ett exempel på \\ ett sådant möte är mötet mellan den döve och den hörande \\ arbetskollegan. Vilken betydelse har vår kulturella förank- \\ ring för mötet på arbetsplatsen? På vilket sätt kan ett \\ kulturpsykologiskt synsätt medverka till att förstå dövas \\ integrering på arbetsplatsen? Detta är några av de frågor \\ som artikeln belyser.
}

\section{Att vara eller inte vara förankrad i arbetskulturen}

Kulturen utgör, åtminstone delvis, en måttstock för hur en individ hanterar sin perceptuella värld. Kulturen överförs via familjen. Mycket av kulturöverföringen sker icke-verbalt. Kultur kan uppfattas som ett kollektivt uttryck för en grupps personlighet, dvs. gruppens önskningar, värderingar och ideologi (se vidare i Backenroth-Ohsako, 1998). Kultur definieras enl. Geert Hofstede (1980) som ett kollektivt mentalt program som uppstår i den specifika miljö som individen verkar. Utifrån detta synsätt på kulturen följer att kultur inte kan uppfattas som en disposition hos den enskilde indi-

Gunnel Backenroth-Ohsako är docent i psykologi, leg. psykolog och specialist i klinisk psykologi, och verksam som forskare, lärare - dels vid Karolinska Institutet på Huddinge Universitetssjukhus och dels vid Psykologiska institutionen vid Stockholms Universitet. viden. Det handlar snarare om ett förhållningssätt som delas av ett stort antal individer som har blivit utsatta för liknande miljöpåverkan och individer som har gemensamma livserfarenheter. I föreliggande artikel ligger fokus på kulturmöten där integrationens vara eller icke-vara belyses utifrån några exempel som är hämtade från den egna forskningen med döva resp. hörselskadade. Integrering definieras som känslan av delaktighet och tillhörighet iarbetsgruppen, såväl fysisk som känslomässig, social och kulturell delaktighet. Det empiriska underlaget baseras på kvantitativt resp. kvalitativt material som har insamlats. Materialet är hämtat från olika studier, dels med döva och dels med hörselskadade, och utgörs av halvstrukturerade intervjuer som genomförts på teckenspråk resp. på talspråk. Först en definition av vad begreppet döv innebär.

Att vara döv innebär inte att man med automatik vinner medlemsskap $i$ dövgruppen. Dövgruppen är inte en grupp, det 
finns många olika grupperingar inom den s.k. dövvärlden. Det är främst användningen av teckenspråk och attityderna till teckenspråk, hur man förhåller sig till andra döva resp. till hörande (se vidare Backenroth, 1998) som definierar en person med döv identitet. Man kan som hörselskadad identifiera sig med döva och sträva efter att betraktas som döv. Men att bli betraktad som döv kräver också att andra uppfattar och accepterar att man besitter de nödvändiga attribut som utgör inträdesbiljetten till dövvärldenı. Motsvarande gäller också, det finns döva som har en hörselskadeidentitet och som vill identifiera sig med gruppen hörselskadade och känna sin tillhörighet där. I vissa fall blir skillnaderna mellan olika tillhörighetsgrupper oerhört viktig, i andra fall kan den knappast skönjas. Stephen Bochner och Toshio Ohsako (1977) har visat att skillnaden mellan olika grupper inte anses som betydelsefull $i$ vissa kulturer medan det $i$ andra kulturer anses som oerhört viktigt vilken grupp man tillhör. De tar exemplet mellan katoliker och protestanter. Skillnaden mellan att vara katolik resp. protestant är mer uppenbar i ett land som Irland, medan denna skillnad är marginell i t.ex. Australien. Låt oss överföra detta synsätt på dövgruppen: Att tillhöra majoritetsgruppen döva med dövt teckenspråk alternativt ,elitgruppen ‘ döva ${ }^{1}$ inom vilken grupp en del anses som 'hörfina ${ }^{2}$ anses

1 Dvs. döva som behärskar svenska språket och som har förmågan att pendla mellan teckenspråket och svenskt påverkat teckenspråk beroende på vem de talar med.

2 Personer med lindrigare hörselnedsättning och som - eftersom de behärskar teckenspråket betraktas som döva. inte som en viktig distinktion bland vanliga hörande som inte har kontakt med döva, men det utgör en betydelsefull skillnad i dövgruppen. För forskaren på dövområdet är det inte enbart fruktbart utan också nödvändigt att förstå de små betydelsebärande skillnaderna. Det förutsätter både lyhördhet, samarbete med döva kollegor och kontinuerlig uppdatering av sin dövkulturkompetens.

\section{Avsaknad av förankring}

En del döva har täta sociala nätverk, andra har mer eller mindre glesmaskiga sociala nätverk. En mycket marginell grupp döva har en avsaknad av sociala nätverk. Det finns både döva och hörselskadade som lever och verkar utanför sin egen tillhörighetsgrupp. En del döva hamnar utanför dövgruppen av eget val eller av påtvingade skäl. De kan ha haft tillfredsställande nätverk som av av olika skäl har upphört att fungera. Några orsaker till att döva hamnar utanför sin egen tillhörighetsgrupp är t.ex. social blyghet. Dåligt självförtroende. Psykiska problem. Misstänksamhet. Felı skolbakgrund och ,fel teckenspråk. Icke-accepterandeattityder till dövhet. Udda personlighet. „Fel« social bakgrund. Bristande social kompetens (Backenroth, 1993). Som hörande kan vi välja mellan fleraolikagrupper för social samvaro. Döva har en grupp - dövgruppen. När döva hamnar utanför sin tillhörighetsgrupp slår därför den psykosociala isoleringen obarmhärtigt hårt. Att mista sin hörsel när man står mitt uppe i livet, dvs. att bli avbruten i sitt liv som hörande, innebär förändringar och nya utmaningar. Vuxenhörselskadade och vuxendöva kan också, åtminstone under

Gunnel Backenroth-Ohsako: Kulturmöten mellan döva och hörande... 
perioder, identifiera sig med en avsaknad av förankring i en ny tillhörighetsgrupp. Dvs. personen är fysiskt integrerad på en arbetsplats utan att för den skull uppleva någon psykosocial integrering. Så här berättar en hörselskadad kvinna som beskriver sig vara ointegrerad $i$ arbetsgruppen:

Det har att göra med olika orsaker, min hörselskada. Men också för att jag är välbeställd och har en hög utbildning. Det är svårt ... mina kollegor är för sig själva. Jag får inte ta del av deras värld. Främst p.g.a. min hörselskada ...

\section{Partiell förankring}

Hörselskadade och vuxendöva kan sägas röra sig mellan två kulturer, den hörande kulturen som de växt upp i och levt i större delen av sitt vuxenliv resp. hörselskadegruppen dit många som blivit hörselskadade i vuxen ålder orienterar sig, alternativt dövsamhället som en del vuxendöva söker sig till. Ett begrepp som används för personer som rör sig mellan två kulturer är ımarginalmänniskorı (Furnham \& Bochner, 1986). Marginalmänniskor kan sägas ha ett partiellt medlemsskap i två grupper, men de är inte fullvärdiga medlemmar i vare sig den ena eller den andra kulturen. Både en del döva, vuxendöva, hörselskadade kan karaktäriseras som marginalmänniskor med tveksam förankring i vare sig den ena eller den andra gruppen. Så här beskriver ett par vuxenhörselskadade sina upplevelser i intervjuer med undertecknad:

Att vara hörselskadad är att stå mitt emellan två olika världar. Man hör för bra för att höra dåligt. Men man hör för dåligt för att höra bra»
... Jag är både integrerad och inte integrerad ... Jag känner mig utanför trots att jag inte är det...

Man är ıi skarvenı när man är hörselskadad, man vet inte vart man hör.

Det finns visserligen beröringspunkter med båda kulturerna men förankringen är marginell. Integreringen kan upplevas med ambivalens. Det karaktäristiska för marginalmänniskan som rör sig mellan två kulturer är att det kan finnas konflikter, identitetsförvirring, överkompensation. Nehru beskrivs som den mest kända marginalmänniskan, han upplevde sig som en blandning av både öst och väst, men han kände sig som en främling i båda kulturerna (Furnham \& Bochner, 1986).

\section{Dubbel förankring}

Ett annat begrepp från den kulturpsykologiska litteraturen som man skulle kunna använda om en del döva - snarare döva än hörselskadade eftersom dövgruppen är en sådan distinkt kultur med sitt eget språk och sina egna normer - är medierande dövar. De döva som medierar utgör en länk mellan dövsamhället och det hörande majoritetssamhället. De fungerar som brobryggare, tolkar, förmedlare, katalysatorer mellan två olika kulturer. En medierande döv har förankring, definitionsmässigt, i både dövsamhället och det hörande majoritetssamhället. Man kan säga att personen är välintegrerad i två kulturer. Det finns en överlappning och ett stort gemensamt område som delas av båda kulturerna hos individer som har ett dubbelt medlemsskap, en dubbel för- 
ankring i två kulturella system. Han/hon har också kompetenser som är relevanta för både den döva kulturen och den hörande kulturen $^{3}$. Några hörselskadade personer beskriver sin integrering i arbetsgruppen på följande sätt:

Jag känner mig integrerad. Det är ingen skillnad mellan oss ... Jag skulle säkert uppföra mig annorlunda på arbetsplatsen om jag inte vore hörselskadad, men jag känner mig inte utanför. Jag är en viktig kugge i maskineriet för att det skall fungera. Utan mig är det ... anarki. Jag har en position...

Jag har aldrig känt det som ett problem. Jag tror att jag är lätt som person att ha att göra med. Och de situationer jag möter finner jag mig i...

... Jag är spindeln i nätet på arbetsplatsen och i min arbetsgrupp.

Adrian Furnham och Stephen Bochner (1986) framhåller att enstaka människor, under vissa förhållande och beroende på den position de har i samhället, kan bli framgångsrika medierande män och kvinnor. Karakteristiskt för dessa personer är att de har förmågan att välja, kombinera och syntetisera passande drag från respektive kultur utan att för den skull förlora sin innersta kulturella kärna. Anledningen till att dessa individer ses som medierande är vidare att de har förmågan att utgöra länkar

3 Kunskaper om respektive grupp (historik, traditioner, sedvänjor, värderingar), kommunikationsfärdigheter(teckenspråk resp. godasvenskkunskaper), tekniska färdigheter (akademiska, kulturella), social kompetens (hur man förhåller sig till medlemmar i båda grupperna, officiella/inofficiella regler), personliga egenskaper (intresse, respekt, omsorg om andra, personlig trygghet). mellan olika kulturella system (Furnham \& Bochner, 1986: 31): "...medierande personer överbryggar kulturella klyftor genom att introducera, översätta, representera och harmonisera respektive kulturer till varandra». De döva medarbetare som medverkat i olika forskningsprojekt som undertecknad ansvarat för under årens lopp ger för handen att de tveklöst tillhört gruppen 'medierande döva - sett i backspegeln. Döva kollegor har utgjort en ovärderlig resurs i forskningen. De har varit ett stöd. Ett bollplank. Tillfört stimulans. Kort sagt, de har medverkat till att höja forskarkompetensen. Kulturkompetensen kan inte erövras enbart genom akademiska studier, den måste erövras i naturliga samarbetssituationer. Det erfordras många olika ingredienser i kulturinlärningsprocessen och - inte minst - interaktion med den relevanta kulturmiljön (se Backenroth, 1992).

Deflestafunktionshindrade intar en minoritetsposition i arbetslivet som kan illustreras med att de kastar boll från underläger. Den kulturella förankringen $i$ vår egen grupp och i det icke-funktionshindrade majoritetssamhället säger oss något om vilken roll vi får i arbetslivtet. Alla, oavsett funktionshinder eller ej, har olika psykologiska förutsättningar med sig i bagaget till en arbetsplats. Dessa förutsättningar samspelar med förutsättningarna som finns på arbetsplatsen (arbetsmiljö, arbetsorganisation, ledarskap, arbetsuppgifternas karaktär, arbetsplatsens psykosociala förutsättningar samt vad som sker i samspelet mellan den funktionshindrade personen och hans/hennes arbetsgrupp). En del människor med funktionshinder har välutvecklade sociala kompetenser och har utvecklat en förmåga att kunna relatera och samarbeta med olika

Gunnel Backenroth-Ohsako: Kulturmöten mellan döva och hörande... 
människor. De är öppna, positiva och motiverade att ta kontakt med andra och lära sig saker på en arbetsplats. De vågar ta initiativ. De är ansvarsfulla. De kan hantera missförstånd, besvikelser och konflikter som normalt kan uppstå i en arbetsgrupp på ett moget sätt. De är medvetna om hur de kan uppfattas av andra och använder sig av denna medvetenhet i samarbetet med andra. De kan se arbetssituationer från olika perspektiv. De kan få rollen som ımedierande länkarı i en arbetsgrupp. Oftast har de en trygg förankring både bland icke-funktionshindrade och bland funktionshindrade som tillhör den egna gruppen. Man kan säga att de har ett sdubbelt medlemsskap i vid bemärkelse eftersom de besitter kompetenser som är relevanta för olika kulturella system, kulturer som åtminstone delvis är olika (sett utifrån majoritetssamhället resp. minoritetssamhället).

Arbetsgivare inom olika branscher (industri/bygg, service, offentlig verksamhet) tillfrågades i en enkätstudie, som genomfördes av undertecknad, om sina attityder till vad som karaktäriserar individer som är svårintegrerade på en arbetsplats. Deras svar fokuserade på avsaknad av personliga kompetenser ${ }^{4}$ först och främst och, först iandra hand, påavsaknaden av formella kompetenser $^{5}$ (Backenroth, 2000). Funk-

4 Att inte 'passa in iı arbetsgruppen beroende på sin personlighet. Att ha en omogen personlighet - inte känna lojalitet med gemensamma mål i organisationen. Bristande flexibilitet. Invandrarbakgrund. Funktionshinder. Socialmedicinska handikapp (alkoholism och drogproblem). Oförmåga att kommunicera; inte vara öppen och tillgänglig, inte kunna etablera kontakt.

5 Avsaknad av arbetsrelaterad kompetens för yrket ifråga. Avsaknad av kunskaper i främmande språk. Att inte behärska dagens datateknik. tionshinder var ett av flera hinder sett utifrån arbetsgivarnas perspektiv vilket skulle kunna tolkas som att samhället, med sitt ökade krav på kompetenser, ställer allt större krav på arbetskraften. Funktionshinder utgör då endast en av många andra barriärer för att få tillträde till arbetsmarknaden.

\section{Synen på funktionshinder $\mathrm{i}$ arbetslivet har inte underlättat möten $i$ arbetslivet}

Bakom begreppet funktionshinder döljer sig individer med många varierande förutsättningar, kompetenser, behov och aspirationer. Mötet mellan individer med resp. utan funktionshinder kan - ibland - ses som ett kulturmöte. Detta gäller dock inte generellt utan blir alldeles särskilt tydligt när döva och hörande möts i arbetslivet. ${ }^{6}$

Den förhärskande synen på funktionshindrade $i$ arbetslivet har inte alltid varit kompetensförstärkande eller inriktat sig på samspelet mellan individen och miljön. Våra attityder till funktionshinder och till vem som är arbetshandikappad eller ej, förefaller vara konjunkturkänsliga. Man kan säga att attityderna, åtminstone delvis, styrs av samhällets marknadskrafter. Många funktionshindrade kollegor kan sägas ha ett sdubbelhandikapp i arbetslivet såtillvida att de skall utföra ett jobb, minst lika bra som andra - kanske t.o.m. lite bättre - samtidigt som de måste hantera sitt funktionshinder i en arbetsmiljö som inte alltid är avpassad efter

6 Eftersom dövas första språk är teckenspråk och döva och hörande endast till en del är förankrade i en och samma kultur. 
deras behov. Vidare kanske många funktionshindrade inte känner samma ffrihetsgrader $i$ arbetslivet när det gäller att ställa krav på åtgärder och förändring. I en tidigare studie av undertecknad (Backenroth, 1996a) tydde resultaten på, utifrån en enkät riktad till hörselskadade, att rehabilitering kan upplevas som ett hinder eller ett stigma i arbetslivet. Detärsvårt för många icke-funktionshindrade kollegor att förstå vad funktionshindrade kollegor kämpar med under loppet av en arbetsdag ${ }^{7}$. Personliga förutsättningar hos individen påverkar känslan av socialt utanförskap hävdar John Bynner (1999). En individualpsykologisk syn på funktionshinder är dock otillräcklig för att förstå den funktionshindrade personens position argumenterarPaul Abberley(1996), eftersom detta synsätt lokaliserar whandikapproblematiken" till individen, t.ex.hans/ hennes anpassning till en viss uppsättning av värderingar och beteenden vilka tas för givet. Man skulle kunna säga att detta synsätt förlägger orsaken till problemen i den funktionshindrade personens personliga utrustning och inte tar med i beräkningen omgivningen eller individens samspel med sin miljö. Abberlys förklaring är att funktionshindrade personer, om de uppvisar psykologiska avvikelser, inte är att klandra eftersom samhället har socialiserat dem till sådana drag som ett resultat av hur samhället bemöter den funktionshindrade indi-

7 T.ex. att få känna tillhörighet i arbetsgruppen, att få arbetsuppgifter som inte ligger under deras kompetensnivå, att få information, att få stöd och vägledning vid behov, att hålla utvecklingstakten, att få möjligheter till kompetensutveckling, att behålla fotfästet på arbetsmarknaden. viden och hans/hennes behov. Vidare understryker han att de psykologiska kostnader funktionshindrademänniskor betalar måste identifieras som en aspekt av förtryck. Joy Lenny (1996)är inne på samma tankegångar som Abberly när han framför synpunkten att många funktionshindrade konfronterar samhällets experter och experternas antagande om vad funktionshindrade behöver. Bakom erbjudandet av 'counselling, ${ }^{8}$ finns antaganden om att den funktionshindrade har emotionella, psykologiska och personliga problem som måste bearbetas i terapi (Lenny, 1996).

I arbetslivet utgör den icke-funktionshindrade arbetskraften majoriteten och den funktionshindrade arbetskraften minoriteten (utifrån ett ımainstream-minorityı synsätt). Att människor har olika erfarenheter från arbetslivet och, åtminstone delvis, tillhör olika grupper kan påverka perceptionen och interaktionen med andra människor $\mathrm{i}$ arbetsgruppen.

För inte så länge sedan tillbaka fyllde många individer med funktionshinder av tradition vissa nischer på arbetsmarknaden. Idag bryter de ny mark genom att vinna terräng på sådana områden som sjukvård, omsorg, forskning, utbildning, vägledning. Dessvärre leder inte fysisk integrering nödvändigtvis till psykosocial integrering på arbetsmarknaden.

På den internationella forskningsarenan hävdas att funktionshindrade, som grupp betraktat, dels har en svagare position på arbetsmarknaden och dels kan hamna i riskzonen för marginalisering (Brown, 1990, Yan et al, 1993, Mannila, 1995, 1996) och

9 (Terapi, råd, vägledning).

Gunnel Backenroth-Ohsako: Kulturmöten mellan döva och hörande... 
utanförskap (Abrahamsson, 1995, Backenroth, 1996b). Även om många människor med svåra funktionshinder lever i samhällets gränsland och riskerar att marginaliseras, finns det personer med funktionshinder som - visserligen i varierande grad men mer framgångsrikt än andra-är integrerade psykologiskt och socialt i arbetslivet.

Integrering och inklusion är två begrepp som ofta används för att beskriva interaktionen mellan funktionshindrade och icke-funktionshindrade. Inklusion definieras som den handling som försöker inbjuda individen till att bli en del av gruppen. ${ }^{9}$ Inklusion är motsatsen till exklusion. Och någonting skilt från marginalisering, isolering, separat. Inklusion omfattar både ickefunktionshindrade och funktionshindrade arbetstagare som, var och en, har möjligheten att medverka på arbetsplatsen i en tillfredsställande arbetsmiljö. Arbetsmiljön avser både fysiska och psykosociala aspekter.

Med integration avses definitionsmässigt någon som integreras $i$ en social grupp genom att han/hon beter sig på ett sådant sätt att de blir en del av gruppen eller accepteras som en i gruppen. Om något integreras med något annat, kombineras det första med det andra så att dessa delar utgör delar av ett och samma system. ${ }^{10}$

Assimilering som en form av integrering har, enl. John Berrys (1991) erfarenheter inte fungerat i något land $i$ vår samtid. Den

9 Collins Cobuild English Dictionary (1999). The University of Birmingham: Harper Collins Publ. Ltd.

10 Collins Cobuild English Dictionary (1999). The University of Birmingham: Harper Collins Publ. Ltd. flerkulturella teorin däremot försöker generera kunskap om hur integrering av minoritetsgrupper i ett samhälle kan ske på ett mer framgångsrikt sätt. De grundläggande principerna för 'multikulturalismenı grundar sig på att detta synsätt förenar både kulturgenerella och kulturspecifika element. Integrering och differentiering är, hävdar Paul Pedersen (1991), komplementära processer i en och samma teori.

Vilkasynsätt skullekunna underlättakulturmöten i framtidens arbetsliv?

Det interaktionistiska perspektivet (se Magnusson, 1988) skulle kunna ha ett substantiellt bidrag till synen på den funktionshindrade, till förståelsen för mötet mellan den funktionshindrade och den icke-funktionshindrade $i$ arbetslivet. Interaktionismen betonar den ömsesidiga påverkan av situationella och dispositionella faktorer hos individen. Teorin tar sin startpunkt $i$ antagandet att individen (t.ex. den funktionshindrade individen), situationen ( $t$.ex. arbetssituationen, den fysiska såväl som den psykiska), och interaktionen mellan dessa båda är viktiga determinanter för en individs upplevelser och beteenden. Ett interaktionistiskt synsätt utgår från uppfattningen att individen och situationen är en oförenlig enhet. Ur ett interaktionistiskt perspektiv kan man beskriva varje individs socialiseringsprocess till en roll $i$ arbetslivet som tidigt etablerad i livet men med fortsatt utveckling i interaktion med arbetslivet inom ett givet socialt och kulturellt kontext. Varje funktionshinder är unikt och varje person med ett funktionshinder är unik. Därtill är varje samspelssituation i arbetslivet unik. Funktionshindrade människor är både mottagare och aktiva agenter $\mathrm{i}$ 
denna interaktionsprocess som äger rum på arbetsplatsen, dvs. de influeras av arbetsmiljön men kan också själva påverka interaktionerna med sin sociala omgivning. Det interaktionistiska perspektivet har i otillräcklig grad tillämpats när det gäller viktiga frågor om samspel och integration $i$ arbetslivet. Bedömningen av kvaliteten av social integration är dock inte lätt. Dels är det svårt att hitta en entydig definition och dels är det svårt att hitta ett instrument som kan fånga upp begreppets komplexitet. Integration anses innefatta både en fysisk och social komponent och definieras i det specifika jobb-kontextet. Några forskare (Parent et al, 1991) har försökt konstruera ett index som syftar till att bedöma ett antal olika integrationskarakteristika på en arbetsplats samt till vilken grad den funktionshindrade individen ${ }^{11}$ upplever fysisk och social integration på arbetsplatsen. Instrumentets värde förefaller ligga främst i sin kliniska tillämpning inom t.ex. den verksamhet som arbetsförmedlingarna bedriver.

Andra synsätt som skulle kunna tillämpas för att förstå och förändra den funktionshindrades position i arbetslivet är kulturella mångfaldsteorier. Kulturen förmedlas via familjen. Vi kan inte direkt observera hur kulturöverföringen går till menar Lawrence Stone och Joseph Church (1973) för många aspekter av kulturen förmedlas implicit, utan ord. Kulturtillhörigheten är både en mäktig men subtil determinant i en individs perceptuella, kognitiva värld och $i$ hennes/hans beteendemönster. Resultatet av en ökad medvetenhet om det mångkulturella samhället har gjort att psykologisk teori

11 Supported employment workers har kommit att inbegripa ett kulturpsykologiskt synsätt för att fånga samspelsfaktorer. Detta synsätt representeras av många forskare (däribland Bochner, 1981; 1986; Bartz et al, 1990; Van Den Bergh, 1990; Berry, 1991; Pedersen, 1991; Thomas, 1991; 1995; Triandis, 1995) och "multiculturalism « dvs. mångfald - är ett begrepp som ingår under paraplyet ılikhetı (ıdiversity`). Det är olikhetsperspektivet (Thomas, 1995) som kan ge styrka i organisationer och arbetsledning i framtiden. T.ex. hur man bygger upp nätverk. Hur man genomför förändringar på en arbetsplats. Hur man löser konflikter.

, Empowerment- begreppet ${ }^{12}$ är ett annat synsätt som måste genomsyra olika nivåer av åtgärder. Icke-traditionella åtgärder krävs för att stärka funktionshindrade personers position på arbetsmarkanden har Stig Larsson (1996) hävdat. Även Simo Mannila (1996) har understrukit vikten av nya initiativ för anställning och integrering av marginella grupper på arbetsmarknaden. Ledarskapet har också betydelse för den funktionshindrade på arbetsmarkanden eftersom ledaren i en organisation kan ha en nyckelroll, fungera som en mentor $i$ arbetslivet och överbrygga den kulturella klyfta som kan finnas mellan funktionshindrade och icke-funktionshindrade kollegor (Backenroth, 2000).

För att genuina kulturmöten skall kunna möjliggöras i arbetslivet mellan funktionshindrade ochicke-funktionshindrade måste personer med funktionshinder synliggöras ytterligare på arbetsmarknaden. Tänk om det kunde bli en merit för arbetsgivare i

12 Bemyndiga, ackreditera medarbetarna. Erbjuda dem möjligheter att vara delaktiga i processen.

Gunnel Backenroth-Ohsako: Kulturmöten mellan döva och hörande... 
framtiden att anställa funktionshindrade arbetstagare och öka mångfalden i arbetsgruppen!Många funktionshindrade har inte kastat boll från samma planhalva i arbetslivet och har-om de alls varit med i samma lag - oftast kastat boll från underläge. $\mathrm{Nu}$ måste icke-funktionshindrade kollegor fånga upp och ta emot bollen - resurserna och uppskatta det bidrag som funktionshindrade kollegor tillför laget dvs. arbetsgruppen. Detta förutsätter nya organisationsmodeller, stödsystem, sociala nätverk på arbets- platsen. Gruppen funktionshindrade människor utgör $e n$ aspekt av samhällets mångfald. Har vi råd att ha en arbetsmarknad i framtiden som vänder sig till konsumentgrupper i ett pluralistiskt samhälle utan att använda oss av funktionshindrade människors resurskapital? Kanske kan forskningen i framtiden bidra till att arbetslivet ser möjligheter i denna sammansättning på arbetsplatsen? Kanskekommer forskning att kunna påvisa att social integrering kan höja livskvaliteten för oss allesammans?

\section{Litteratur}

Abberley, Paul (1996). Disabled people and "normality". In J. Swain, V. Finkelstein, S. French \& M. Oliver, Disabling barriers - enabling environments (pp. 107-115). London: Sage Publications.

Abrahamsson, Kenneth (1995). Strukturomvandlingen och de utsatta (Structural changes and the vulnerable groups). I M. Utbult \& B. Frejhagen(red.), Det nyakompetenslyftyet. Idéskriftom utvecklingavarbetsplatserochanställdaiSverige och Europa (s. 6-11). Stockholm: Arbetsmiljöfonden.

Backenroth, Gunnel (1992). Cultural competence in training professionals working in the deaf culture. Paper presented at the 43rd session of the International Conference on Education (ICE). "Contribution of Education to cultural development", September 14-19. Geneva: UNESCO.

Backenroth, Gunnel (1993). Loneliness in the deaf community - a personal choice or an enforced choice? International Journal of Rehabilitation Research, 16, 331-336.

Backenroth, Gunnel (1996a). Hörselskadades anpassning och rehabilitering på arbetsplatsen. Svensk översättning. (Hearingimpaired. People's adaption and rehabilitation at the work place). Stockholms universitet: Psykologiska institutionen, 89 .
Backenroth, Gunnel (1996b). Disabilities in working life-a review of Swedish research and some theoretical considerations. European Psychologist, 4, 278-292.

Backenroth-Ohsako, Gunnel (1998). Multiculturalism and the deaf community. Examples given from deaf people working in bicultural groups. In P. Pedersen (Ed.), Multiculturalism as a fourth force (pp. 111-146). Philadelphia, PA: Brunner/ Mazel.

Backenroth, Gunnel (2000). Managers' need for competencies - some implications for the disabled work force. Stockholm University: Reports from the Department of Psychology, No. 863.

Bartz, David E., Hillman, Larry W., Lehrer, Sande, Mayhugh, Gilbert M. (1990). A model for managing work force diversity. Management Education and Development, 21, 321-326.

Berry, John W. (1991). Understanding and managing multiculturalism: Some possible implications of research in Canada. Psychology and Developing Societies, 3, 17-49.

Bochner, Stephen, Ohsako, Toshio (1977). Ethnic role salience in racially homogeneous and heterogeneous societies. Journal of Cross-Cultural Psychology, 8, 477-492.

Bochner, Stephen (Ed.) (1981). The mediating person: Bridges between cultures. Cambridge, 
MA: Schenkman

Bochner, Stephen (1986). Coping with unfamiliar cultures: Adjustment of culture learning? Australian Journal of Psychology, 38, 347-358.

Brown,Philip,M.(1990). Biracial identity and social marginality. Child and Adolescent Social Work, 7,319-337.

Bynner, John (1999). New routes to employment: Integration and exclusion. In W. R. Heinz (Ed.), From education to work. Cross-national perspectives (pp. 65-86). New York: Cambridge University Press.

Furnham, Adrian, Bochner, Stephen (1986). Culture chock. Psychological reactions to unfamiliar environments. London: Routledge.

Hofstede, Geert (1980). Culture's consequences. Beverly Hills, CA: Sage Publications.

Larsson, Stig (1996). De funktionshindrade och arbetsmarknaden (The disabled and the labour market). I M. Tideman (Ed.), Funktionshinder och handikapp (p. 273-299). Stockholm: Johansson \& Skyttmo Förlag.

Lenny, Joy (1996). Do disabled people need counselling? In J. Swain, V. Finkelstein, S. French \& M. Oliver, Disabling barriers - enabling environments (pp. 233-241). London: Sage Publications.

Magnusson, David (1988). Individual development from an interactional perspective: A longitudinal study. In D. Magnusson (Ed.), Paths through life. Vol. 1. Hillsdale, NJ: Lawrence Erlbaum.

Mannila, Simo (1995). Factors influencing the disabled's employment in the competitivelabour market. International Journal of Rehabilitation Research, 18, 19-25.

Mannila, Simo (1996). Social firms in Europe. Some practical aspects. STAKES. Helsinki, Finland: National Research and Development Centre for
Welfare and Health.

Parent, Wendy, Kregel, John, Wehman, Paul, \& Metzler, Helen (1991). Measuring the social integration of supported employment workers. Journal of Vocational Rehabilitation, 1, 35-49.

Pedersen, Paul (1991). Multiculturalism as a generic approach to counseling. Journal of Counseling and Development, 70, 6-12.

Stone, Lawrence Joseph, Church, Joseph $3^{\text {rd }}$. ed. (1973). Childhood and adolescence. A psychology of the growing person. New York: Random House.

Thomas, R. Roosevelt, Jr. (1991). Beyond race and gender: Unleashing the power of your total work force by managing diversity. New York: Amacom.

Thomas, R. Roosevelt, Jr. (1995). Diversity framework. In M. M. Chemers, S. Oskamp, \& M. A. Costanzo (Eds), Diversity in organizations. New perspectives for a changing workplace (pp. 245-263). Thousands Oaks, CA: Sage Publications.

Triandis, Harry C. (1995). A theoretical framework for the study of diversity. In M. M. Chemers, S. Oskamp, \& M. A. Costanzo (Eds), Diversity in organizations. New perspectives for a changing workplace (pp. 11-36). Thousands Oaks, CA: Sage Publications.

Van Den Bergh, Nan (1990). Managing biculturalism at the workplace: a group approach. Social Work with Groups, 13, 71-84.

Yan, Xiaoyan, Mank, David, Sandow, Dennis, Rhodes, Larry, \& Olson, Deborah (1993). Coworkers perceptions of an employee with severe disabilities: An analysis of social interactions in a work setting. Journal of the Association for Persons with Severe Handicaps, 18, 282-291.

Gunnel Backenroth-Ohsako: Kulturmöten mellan döva och hörande... 


\section{Summary \\ Cultural encounters between the deaf and the hearing at the work scene}

Today we have an increased knowledge of how we can make use of our cultural resources. Paradoxically, we make little use of this knowledge. The aim of this article is to present some perspectives which might contribute to the understanding of disabled persons' opportunities for social inclusion at the work scene. The starting point suggests that the work scene gives an opportunity for a cultural encounter between the deaf and the hearing. A cultural encounter may or may not contribute to social inclusion at the workplace. Identifying disabled persons' cultural affiliation may increase our understanding of how successful social inclusion may turn out. Examples are given from research with deaf and hearing-impaired persons. An individual's competence profile may also enhance or obstruct the person's social inclusion in the work group.
The prevailing view of disabled persons in our society has not been competenceenhancing or focusing on their resources or on what they might contribute. By applying an interactionist perspective we can appreciate the disabled person as an active agent interacting with and influencing his or her environment. Fostering empowerment at all levels in society is emphasized as well as looking at old problems in a novel way.

Managing diversity at the work scene has to do with, among other things, versatile leadership, a bicultural approach, bridging and creating a work atmosphere where development and quality of life are achieved for all employees, both those representing the majority culture and those representing the minority culture. 